\title{
Recent Advances of Surfactant-Polymer (SP) Flooding Enhanced Oil Recovery Field Tests in China
}

\author{
Chen Sun, ${ }^{1}$ Hu Guo, ${ }^{1,2}$ Yiqiang Li $\mathbb{D},{ }^{1}$ and Kaoping Song $\mathbb{D}^{1}$ \\ ${ }^{1}$ State Key Laboratory of Petroleum Resources and Prospecting, China University of Petroleum-Beijing, Beijing 102249, China \\ ${ }^{2}$ School of Petroleum Engineering and Environment Engineering, Yan'an University, Yan'an 716000, China
}

Correspondence should be addressed to Yiqiang Li; liyiqiang@cup.edu.cn and Kaoping Song; skpskp01@sina.com

Chen Sun and Hu Guo contributed equally to this work.

Received 19 November 2019; Revised 1 May 2020; Accepted 11 May 2020; Published 26 May 2020

Academic Editor: Jaewon Jang

Copyright ( 92020 Chen Sun et al. This is an open access article distributed under the Creative Commons Attribution License, which permits unrestricted use, distribution, and reproduction in any medium, provided the original work is properly cited.

\begin{abstract}
Recently, there are increasing interests in chemical enhanced oil recovery (EOR) especially surfactant-polymer (SP) flooding. Although alkali-surfactant-polymer (ASP) flooding can make an incremental oil recovery factor (IORF) of $18 \%$ original oil in place (OOIP) according to large-scale field tests in Daqing, the complex antiscaling and emulsion breaking technology as well as potential environment influence makes some people turn to alkali-free SP flooding. With the benefit of high IORF in laboratory and no scaling issue to worry, SP flooding is theoretically better than ASP flooding when high quality surfactant is available. Many SP flooding field tests have been conducted in China, where the largest chemical flooding application is reported. 10 typical large-scale SP flooding field tests were critically reviewed to help understand the benefit and challenge of SP flooding in low oil price era. Among these 10 field tests, only one is conducted in Daqing Oilfield, although ASP flooding has entered the commercial application stage since 2014. 2 SP tests are conducted in Shengli Oilfield. Both technical and economic parameters are used to evaluate these tests. 2 of these ten tests are very successful; the others were either technically or economically unsuccessful. Although laboratory tests showed that SP flooding can attain IORF of more than 15\%, the average predicted IORF for these 10 field tests was 12\% OOIP. Only two SP flooding tests in (SP 1 in Liaohe and SP 7 in Shengli) were reported actual IORF higher than 15\% OOIP. The field test in Shengli was so successful that many enlarged field tests and industrial applications were carried out, which finally lead to a commercial application of SP flooding in 2008. However, other SP projects are not documented except two (SP7 and SP8). SP flooding tests in low permeability reservoirs were not successful due to high surfactant adsorption. It seems that SP flooding is not cost competitive as polymer flooding and ASP flooding if judged by utility factor (UF) and EOR cost. Even the most technically and economically successful SP1 has a much higher cost than polymer flooding and ASP flooding, SP flooding is thus not cost competitive as previously expected. The cost of SP flooding can be as high as ASP flooding, which indicates the importance of alkali. How to reduce surfactant adsorption in SP flooding is very important to cost reduction. It is high time to reevaluate the potential and suitable reservoir conditions for SP flooding. The necessity of surfactant to get ultra-low interfacial tension for EOR remains further investigation. This paper provides the petroleum industry with hard-to-get valuable information.
\end{abstract}

\section{Introduction}

Surfactant-polymer (SP) flooding has advantages of both mobility control and increasing capillary number due to increased viscosity of displacement phase and reduced interfacial tension (IFT), which are key mechanisms of enhanced oil recovery (EOR) in polymer flooding and surfactant flooding, respectively. Sweep efficiency can be significantly enlarged by reduced mobility ratio of displacement phase (water) divided by displaced phase (oil), while displacement efficiency can be largely increased by reducing IFT to ultralow level [1]. SP flooding has combined advantages of polymer and surfactant, while it can avoid the disadvantage of scaling in alkali-surfactant-polymer (ASP) flooding [2-5]. Recently, there are increasing interests of SP flooding in China [6-12]. Evaluation of field tests changes to the criteria and perspective, while incremental oil recovery factor (IORF) is the most frequently used and well-accepted parameter in 
China. It should be noted that this method cannot reflect the cost regarding to the oil price. IORF by polymer flooding in field tests is 7\%-14\% OOIP [13], while ASP can enhanced oil recovery by $18-30 \%$ OOIP according to field tests in Daqing [14]. Typical SP flooding can increase oil recovery by more than 15\% OOIP [15]. SP flooding is believed the development trend of chemical flooding in China $[13,16]$, and five large-scale field tests have been carried out by China National Petroleum Company (CNPC) since 2011 [13]. Although a successful single-well SP field test was reported in Hungary [17], large-scale SP flooding field tests were only reported in China. A critical review and comparison of recent largescale SP flooding field tests in China is of importance but not found yet. This paper reviews 10 major SP flooding field tests in China which includes one offshore field test.

\section{EOR Mechanisms}

A brief introduction about the EOR mechanism is helpful to understand EOR field tests [18]. The basic mechanism of SP flooding includes increase displacement efficiency and enlarging sweep volume. Displacement efficiency is mainly determined by interfacial tension, wettability, and microscopic heterogeneity while sweep efficiency is affected by mobility ratio, macroscopic heterogeneity, and well pattern [1]. It is notable that effective displacement is based on effective contact or sweep. Polymer can increase sweep efficiency significantly. Polymer's effect on displacement efficiency remained disputed. Surfactant can increase displacement efficiency when oil-water interfacial tension (IFT) is reduced to ultra-low. However, surfactant flooding has limited IORF because it cannot increase sweep efficiency due to poor mobility control. ASP flooding can both increase displacement efficiency and sweep efficiency thus can make a very high IORF. SP flooding has advantages of both polymer flooding and surfactant flooding, and most benefits of ASP flooding. Polymer can improve the mobility ratio between the displacing phase (water or polymer solution) and displaced phase (oil), which has been under investigation for decades. Polymer effect on the reduction of residual oil saturation (ROS) has been deemed limited or negligible for a long time until recently. The polymer effect on displacement efficiency due to the viscoelasticity effect is drawing more and more attention [19-25], while its mechanism explanation is not satisfactory or even contradictory [19]. Some researchers investigate microscopic residual oil remobilization mechanisms [26-30]. However, the claimed displacement improvement due to polymer viscoelasticity and normal stress difference $[25,31]$ is not inconsistent with other researchers' observation [19]. Wettability alternation by polymer may be partly responsible for ROS [19]. Mistaking the remaining oil for residual oil accounts for many reported significant ROS reduction in core flooding tests [2]. SP flooding mechanisms are believed quite similar to ASP flooding [10, 15]. Mechanisms of ASP flooding includes reduction of water mobility by polymer $[21,32]$, reducing IFT by surfactants added or/and in situ produced [33-37], wettability alternation due to alkali and surfactants [32, 38], and emulsification [39-44]. Although the detailed contribution degree of emulsification due to addiction of alkali in ASP flooding is still unknown, it is well accepted that emulsification plays a very important role in chemical flooding [45-48]. Surfactant adsorption can be reduced by $50 \%$ or less by the polymer in SP flooding due to competitively adsorption between surfactants and polymers [49]. However, the surfactant reduction in SP (less than $50 \%$ ) is much smaller than ASP (surfactant adsorption reduced to almost zero) $[50,51]$. Surfactant adsorption differs in SP and ASP flooding [2-4]. The laboratory screening of polymers and surfactants are available in some references [52-59] while it is not the emphasis of this paper.

\section{Field Tests}

Since the laboratory study of core flooding or flow test has some limitations in reflecting actual reservoir conditions, the field test is not only necessary but also the best way to check technology application $[60,61]$. The field tests can also verify that whether conclusions from laboratory test results are correct. Typical ten SP flooding field tests (SP1 to SP10) in China are summarized to help understand the benefits and challenges of SP flooding. Outside China, few SP flooding field tests are reported in recent years except one in Hungary [17], although many micellar flooding field tests have been conducted decades ago in the USA [1]. The surfactant cost was too high to be used in high surfactant concentration micellar flooding. This is the background of surfactant-polymer flooding attractiveness in recent years. For convenience, ten SP flooding field tests in Tables 1 and 2 are named SP1 to SP10. SP1 to SP5 are organized and implemented at the same time by CNPC $[10,12$, $15,62,63]$. Among these field tests, only SP10 is in the offshore heavy oil reservoir [64-66]. This field test was changed from an offshore polymer flooding field test [67-69]. SP7 and SP8 are both in heavy oil reservoirs in Shengli, SINOPEC [70-72], while the other 7 field tests are all light oil. Typical laboratory screenings for surfactants and polymer are available in reference [73]. Other references [74-83] are also reviewed for more information of SP7 and SP8. SP7 is well introduced in a reference [70]. SP6 [84-90] was carried out in central China in He'nan Oilfield, a subcompany of SINOPEC. SP9 in Daqing Oilfield is carried out in postpolymer flooding reservoirs [9194]. These 10 field tests are not the whole SP flooding field tests in China, but most typical ones that can be found. These field tests are the ones that can be accessible to publications. Many SP flooding field tests, especially in Shengli Oilfield, are not well documented due to many reasons including technology protection considerations.

Basic information of reservoir formation and chemical flooding schemes of these tests are given in Tables 1 and 2 . Since polymer flooding is mature in China and other places except some harsh reservoirs like high temperature and carbonate reservoirs, we do not focus on the polymers in this paper. However, it is worth to mention that all polymer used in these ten field tests are synthetic polymers (Partially hydrolyzed polyacrylamide, HPAM) and only in one (SP9) is associate polymer. Although surfactant flooding is reported decades ago [1], commercial use of surfactant in EOR is still not well documented. About the surfactant flooding mechanism, one may refer to a critical review on surfactant EOR progress [95]. The surfactant type and performance is of vital 
TABLE 1: Basic information of typical SP flooding field tests in China.

\begin{tabular}{|c|c|c|c|c|c|c|c|c|c|c|}
\hline No. & 1 & 2 & 3 & 4 & 5 & 6 & 7 & 8 & 9 & 10 \\
\hline Oilfields & Liaohe & Xinjiang & Jilin & Changqing & Dagang & He'nan & Shengli & Shengli & Daqing & CNOOC \\
\hline Location & J16 & $7 Z Q$ & $\mathrm{H} 113$ & MLB3 & GX3Q & 438 & GD7 & GD6XB & XQ & $\mathrm{JZ9}-3$ \\
\hline Start time & $\begin{array}{l}\text { May } \\
2011\end{array}$ & $\begin{array}{l}\text { Aug } \\
2011\end{array}$ & $\begin{array}{l}\text { Jan } \\
2010\end{array}$ & Sep 2014 & Mar 2012 & $\begin{array}{l}\text { June } \\
2009\end{array}$ & Sep 2003 & Jan 2006 & Dec 2008 & Oct 2010 \\
\hline Injectors & 24 & 18 & 9 & 16 & 11 & 15 & 10 & 37 & 6 & 8 \\
\hline Producers & 35 & 26 & 16 & 25 & 26 & 20 & 16 & 60 & 12 & Irregular \\
\hline Well pattern & 5 spot & 5 spot & 5 spot & 5 spot & NA & Irregular & Line & $\begin{array}{c}\text { Inverted } \\
9\end{array}$ & 5 spot & $\begin{array}{c}\text { Inverted } \\
9\end{array}$ \\
\hline Well spacing $(\mathrm{m})$ & 150 & 150 & 141 & 150 & $150-200$ & $202-210$ & $300 \times 150$ & $212 \times 106$ & 250 & $350-400$ \\
\hline Area $\left(\mathrm{km}^{2}\right)$ & 1.28 & 1.21 & 0.68 & 1.12 & 0.45 & 0.93 & 0.94 & 2.8 & 1.08 & NA \\
\hline OOIP (10 4 ton) & 298 & 120.8 & 93 & 105.8 & 205.4 & 296 & 277 & 645 & 262.41 & 4874 \\
\hline Strata depth (m) & $\begin{array}{c}1255- \\
1460\end{array}$ & 1146 & 1202 & 1670 & 1300 & 1415 & $\begin{array}{l}1261- \\
1294\end{array}$ & 1350 & $\begin{array}{c}1040- \\
1050\end{array}$ & NA \\
\hline Pressure (MPa) & 12.4 & 16.07 & 7.66 & 13.48 & $\begin{array}{l}9.14- \\
12.85\end{array}$ & 13.8 & 12.4 & 13.37 & 10.3 & $13.4-14.8$ \\
\hline In situ oil viscosity $(\mathrm{cP})$ & 14.3 & 6.0 & 12.9 & 2.3 & $19-37.5$ & 7.6 & 45 & 66.9 & 12.8 & 17.1 \\
\hline Soi $(\%)$ & 60.6 & 70.0 & 64.5 & 65.0 & - & $65-70$ & 72 & 65.8 & NA & NA \\
\hline Acid value (mgKOH/g) & 1.2 & 0.7 & 0.14 & 0.90 & 2.60 & NA & 3.0 & 3.0 & 0.02 & NA \\
\hline Temperature $\left({ }^{\circ} \mathrm{C}\right)$ & 55 & 40 & 55 & 50 & 53 & 67 & 68 & 67.5 & 45 & 57 \\
\hline Porosity (\%) & 29.1 & 17 & 21 & 15 & 31 & 17.5 & 34 & 33.9 & $22-26$ & $22-36$ \\
\hline Permeability (mD) & 3442 & 94 & 115 & 110 & 936 & 569 & 1320 & 1079 & 706 & $10-5000$ \\
\hline $\begin{array}{l}\text { Dykstra-Parsons } \\
\text { coefficient }\end{array}$ & $0.76-1.78$ & $1-2$ & 0.70 & 0.90 & 2.60 & 0.72 & 0.58 & $0.6-0.8$ & 0.72 & NA \\
\hline $\begin{array}{l}\text { Formation brine TDS } \\
(\mathrm{ppm})\end{array}$ & 2467 & 14250 & 15168 & 19000 & 14350 & 2765 & 8307 & 8436 & 4264 & $\begin{array}{c}6401- \\
9182\end{array}$ \\
\hline Brine $\mathrm{Ca}^{2+}+\mathrm{Mg}^{2+}(\mathrm{ppm})$ & 10.4 & 151.2 & 47.3 & 539.0 & 77 & NA & 231 & 195 & 55 & 50 \\
\hline $\begin{array}{l}\text { Injection water TDS } \\
(\mathrm{ppm})\end{array}$ & 2748.9 & 3681.1 & 1200.0 & 5000.0 & 6726.0 & 5012 & 8246 & 7749 & 4012 & 2902 \\
\hline $\begin{array}{l}\text { Inj. water } \mathrm{Ca}^{2+}+\mathrm{Mg}^{2+} \\
(\mathrm{ppm})\end{array}$ & 0 & 43.4 & 20 & 0 & 53 & NA & 276 & 266 & 40 & 30 \\
\hline Predicted IORF (\%OOIP) & 20 & 18.0 & 13.8 & 14.5 & 12.1 & 9.01 & 18 & 9.3 & 6.3 & 6.7 \\
\hline Actual IORF (\%OOIP) & 16.3 & 13.7 & NA & NA & NA & 2 & 16.8 & 6.19 & 2.4 & 1.34 \\
\hline UF & $>45$ & NA & NA & NA & NA & 10.1 & $>49$ & & NA & NA \\
\hline
\end{tabular}

NA: not available.

importance for surfactant EOR. Unfortunately, little information is available about the surfactants used in these ten field tests. Thus, only surfactant type is given in Table 2 according to surveys from various references. Since reducing oil/water IFT to ultra-low is a basic requirement of surfactant in current surfactant screening standard, all surfactants used in these ten field tests are claimed to meet the requirement. The requirement of surfactants and polymers for chemical EOR is available elsewhere [10, 62, 96, 97].

From Table 1, it is obvious most SP flooding field test scale is very large, and one of the main purposes is to develop all the related technologies including surfactants production and evaluation, polymer preparing and injection, and produced fluid processing in actual field sites. All the three national oil companies in China (CNPC, SINOPEC, and CNOOC) have implemented at least one SP flooding field test, indicating that SP flooding is drawing the most attention in China where most chemical EOR happens. Among these 10 typical SP flooding field tests, only Shengli Oilfield from SINOPEC has carried out more than 2 SP flooding field tests (SP7 and SP8). Actually, many other SP flooding field tests and applications in Shengli are implemented but not reported. We will discuss this later. It is also Shengli Oilfield that first carried out SP flooding as well as ASP flooding through large-scale field tests. SP flooding can be regarded as development based on polymer flooding because the polymer make-up process is quite similar. Up to present, polymer flooding is the most wide-used chemical EOR technique in China, and it has been commercially used in Daqing and Shengli in 1996 and 1997, respectively $[8,9,98]$. These two oilfields are also the largest and second-largest oil production companies in China at present. Experience and lessons from polymer flooding provide ideas for SP flooding and ASP flooding. Different from Daqing Oilfield, where polymer 


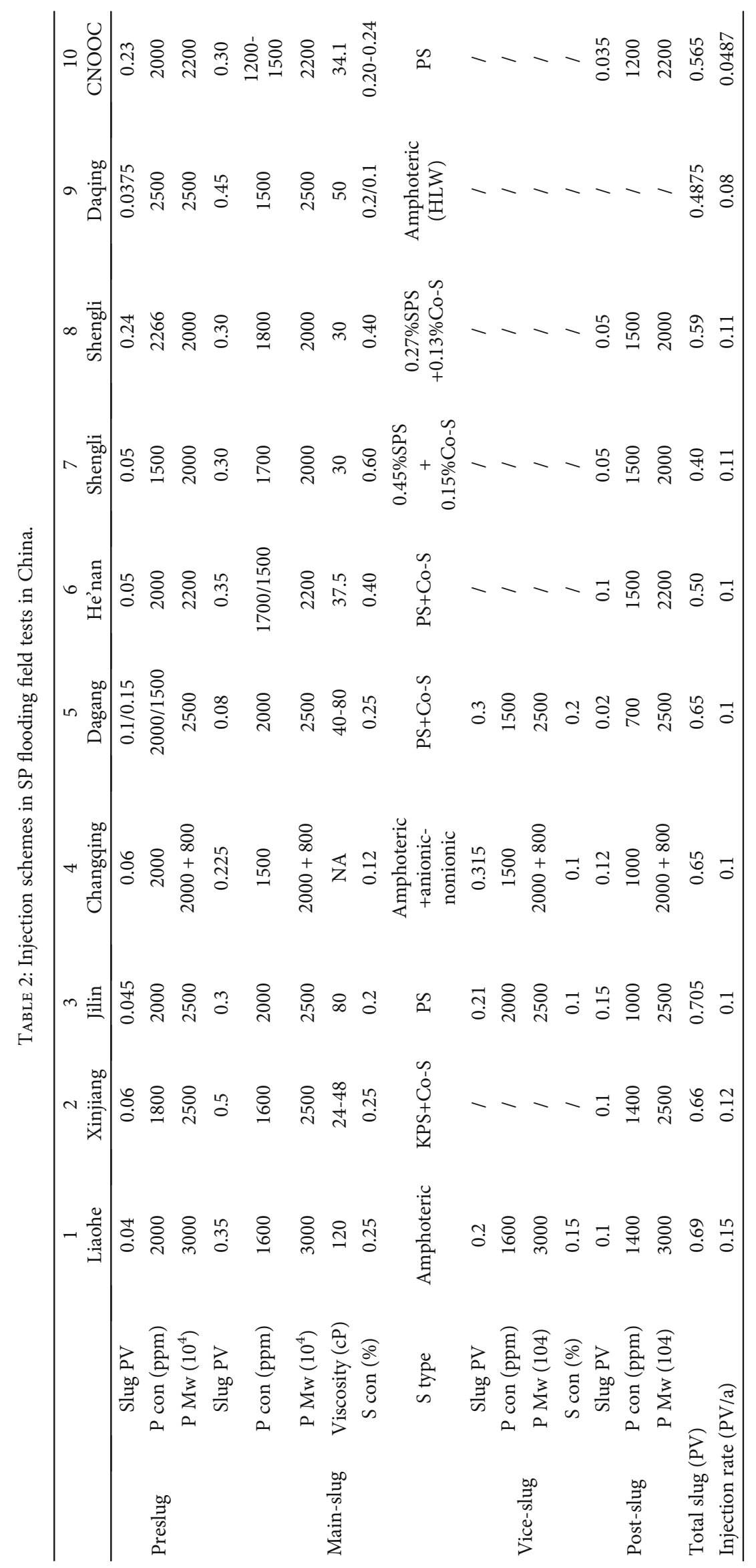




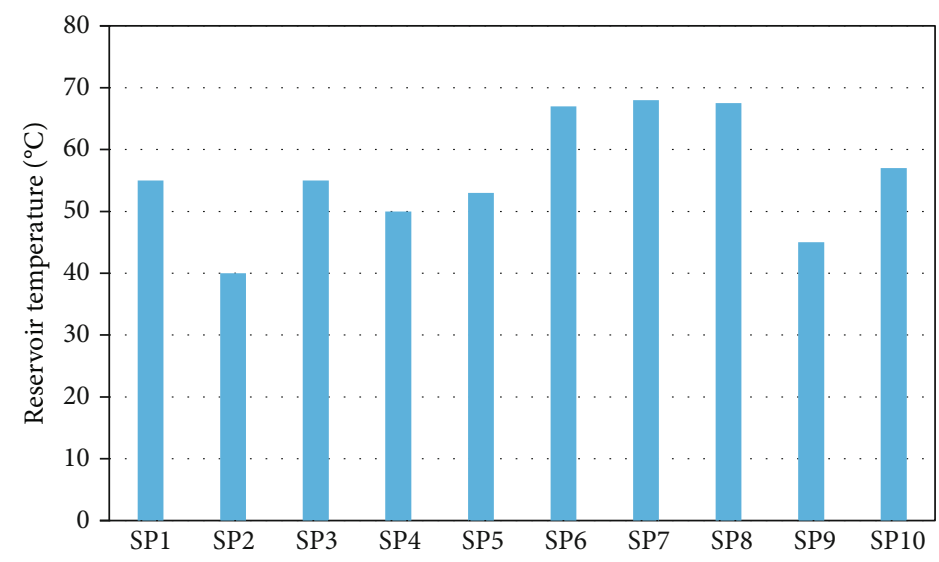

Figure 1: Reservoir temperature of SP field tests.

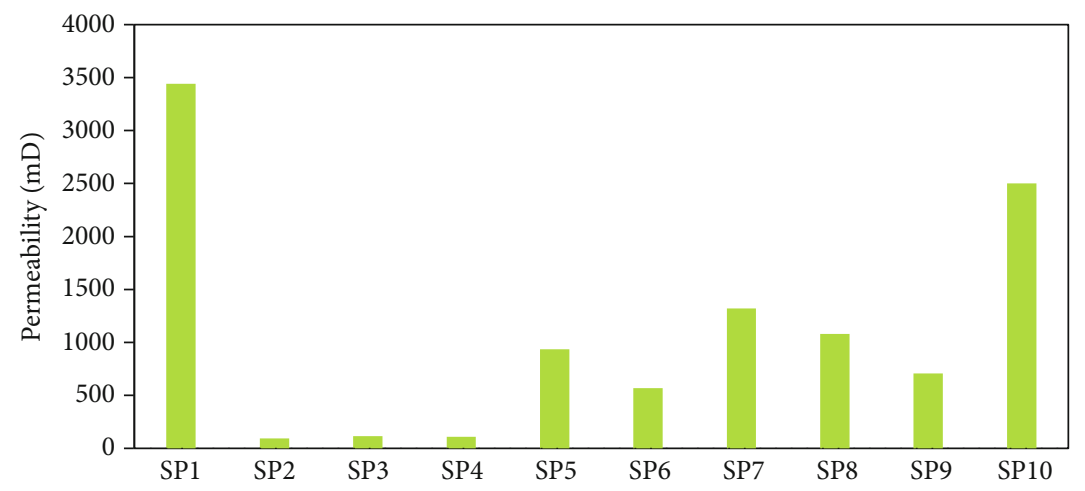

FIGURE 2: Formation average permeability of SP field tests.

flooding has been mature for about twenty years, and ASP flooding has entered into the industrial stage in 2014, Shengli Oilfield has turned to SP flooding after carrying out two large-scale ASP flooding field tests. In 2008, SP flooding was reported to put into industrial use in Shengli. The SP flooding production in Shengli in 2016 is more than 2 million tons [99], which is most in the world to the best of our knowledge.

3.1. Reservoir Petrophysics. Although all the key parameters regarding SP flooding are given in Tables 1 and 2, only the most representative ones such as reservoir temperature, formation permeability, slug size, injection rate, and IORF are discussed here. Some key parameters like Dykstra-Parsons coefficient, well pattern, in situ oil viscosity, and formation brine are not discussed here. As for the 10 SP field tests, 9 are sandstone reservoir and one conglomerate one (SP2). At present, carbonate reservoir chemical flooding is not reported in China, although conglomerate reservoir polymer flooding has been developed recently in Xinjiang Oilfield. The reservoir or formation temperature is shown in Figure 1. Three field tests (SP6, SP7, and SP 8) are in a high-temperature reservoir which is around $68^{\circ} \mathrm{C}$. Other SP flooding is tested in medium or low-temperature reservoir between $40^{\circ} \mathrm{C}$ and $57^{\circ} \mathrm{C}$. Temperature has an important effect on polymer viscosity and thermal stability [100-102]. Laboratory studies and field tests in China indicate that after tem- perature goes higher than $65^{\circ} \mathrm{C}$, some measures have to be taken to reduce or minimize the effect of dissolved oxygen. Thus, it is more challenging for three high-temperature reservoirs to use polymer flooding and SP flooding than others. Permeability is another significant parameter that affects EOR effects. Although chemical flooding EOR techniques have been used in low permeability reservoirs, medium to high permeability reservoirs are better screening candidates according to different screen criteria. Figure 2 shows the average formation permeabilities for these SP field tests. Among these blocks, SP1 is in really high permeable formation $(K=3442 \mathrm{mD})$, and SP10 is generally in high permeability reservoir although this offshore block has wide permeability range. Since SP10 is in high permeability heavy oil reservoir, the permeability of $2500 \mathrm{mD}$ is regarded as the average permeability in Figure 2. It must be mentioned that only a permeability range is given in corresponding references. SP2, SP3, and SP4 have much lower permeabilities than other blocks. SP3 from Changqing Oilfield and SP4 from Jilin Oilfield are typical low permeability reservoirs, and it may have much lower permeability than the values in Table 1 and Figure 2, which are directly collected from references. These two blocks are selected to see whether it is possible to use the ultra-low IFT SP system to develop low permeability reservoirs. Laboratory core flooding tests regarding these tests go well before these field tests are conducted. The laboratory screening of polymers and surfactants for these 


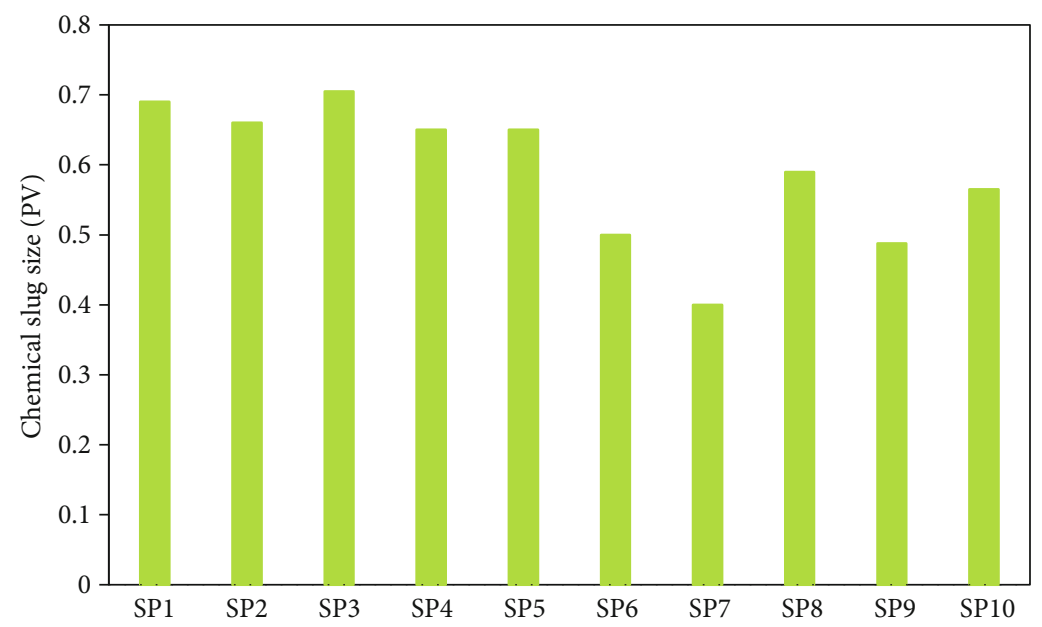

Figure 3: Chemical slug size of SP flooding field tests.

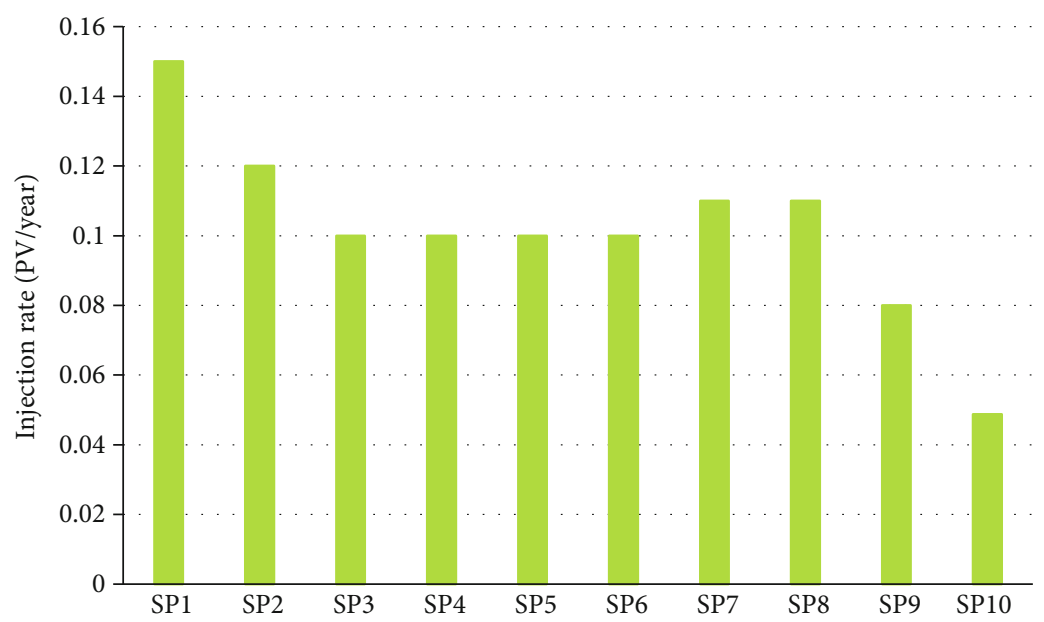

FIGURE 4: Injection rate of SP flooding field tests.

10 SP field tests is beyond the scope of this paper. It is not easy to deploy surfactant flooding in low permeability due to high surfactant adsorption and this will be discussed later.

Chemical slug injected in these tests are shown in Figure 3 and Table 2. SP6 is injected with the least chemical slug among these tests, which have 0.7 PV for most cases. The slug size is determined mainly but not fully by numerical simulation based on reservoir conditions. However, some projects selected chemical slugs more from previous projects rather than other reasons. After all, it is more natural to inject a proper slug similar to a previous block, although the similarity between projects has not been given enough emphasis. If the field test goes as or better than expected, the slug size is usually to be expanded and vice versa. This is based on that fact that polymer flooding cost is much lower than the oil price. This implied that SP6 performance is not good. Figure 4 summarized the injection rate during these field tests. Except the two blocks of SP10 and SP 9, the other injection rate is higher than $0.10 \mathrm{PV}$ per year. The injection rate was believed to affect the recovery factor due to numerical simulation results. However, this depends on the proper geological models that are built and good reservoir simulation.
For chemical flooding projects in China, the injection rate tends to be as high as possible because the operators hope to get positive results. Typical injection rate for polymer flooding is between $0.10 \mathrm{PV}$ per year (PV/year) and 0.15 $\mathrm{PV} /$ year, and $0.20 \mathrm{PV} /$ year only for some very close well (75 $\mathrm{m})$ projects. Among these blocks, SP1 adopted an injection rate of $0.15 \mathrm{PV} /$ year, while 6 blocks used $0.10 \mathrm{PV} /$ year. SP10 is an offshore reservoir, and its injection rate is much lower than onshore ones. SP9 in Daqing is in postpolymer flooding block, and the injection rate is lower than most the other projects in Daqing Oilfield.

Figure 5 shows the reported actual IORFs of these blocks. Note that SP6, SP7, and SP8 have a much higher temperature than others. SP9 is postpolymer flooding block, which is theoretically more difficult for EOR. The expected or predicted IORFs are given in Table 1 and Figure 5. SP1 and SP2 were predicted $20 \%$ and $18 \%$ OOIP, much higher than IORF of $15 \%$ OOIP which is the expectation of SP flooding on some typical reservoir conditions like Daqing. SP2 and SP3 were predicted with high IORF, although their formation permeabilities were much lower than others. Predicted IORF of SP6 and SP8 were lower than others because they have higher 


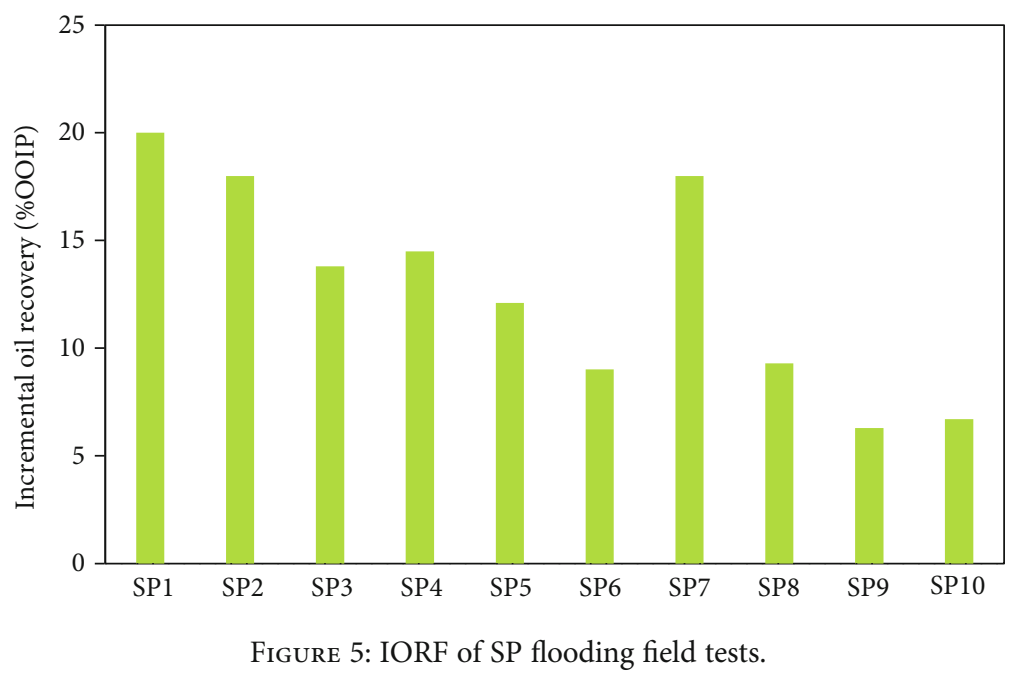

reservoir temperature and oil viscosity. SP7 is an exception considering its high reservoir temperature and higher oil viscosity. SP9 IORF seems lower because this is a polymer flood block. If an IORF of 10\% OOIP was calculated for this Daqing block, the predicted IORF is $16.3 \%$, on the same level as others. Actual IORFs are given in Table 1, and some data are not available. Except for three blocks, actual or updated IORF are lower than the predicted. IORF of SP1 and SP2 in Table 1 are not finally values and according to the references, final incremental oil recovery factor is probably close to or even higher than the predicted value. Some projects are so unsuccessful that they are not further reported. Generally speaking, EOR field tests in China will be reported or published frequently unless they are too unsuccessful to be mentioned. However, all data including some failures are very valuable for the EOR community because they provide valuable references for similar or potential projects. Learning from failures saves lots of money in EOR since any field test involves a huge investment. Although three blocks' IORFs are not available, the information shows that they are much lower than predicted values. Those blocks with poor recovery performance are terminated. SP1 is so successful that a much more enlarged field test has been conducted recently [103].

\section{Performance Evaluation}

How to evaluate field test result is not an easy work. Many factors like reservoir sedimentation characteristics and understanding degree, well pattern and reserve control degree, well drilling quality, development scheme appropriateness, and operator management level affect the development performance $[8,9,11,104]$. Since the OOIP in a certain block is fixed, although sometimes it is changed, the ultimate recovery factor (URF) or IORF compared with waterflooding is often selected as the most important criteria in chemical flooding field practice. Typical SP flooding is believed to enhance oil recovery by $13-17 \%$ OOIP, while polymer and ASP are 8-13\% and 16-22\%, respectively [99]. A recent study shows that ASP flooding IORF can be as high as $30 \%$ OOIP in Daqing $[14,105]$. From Table 1, predicted SP flooding incremental oil recovery can be as high as $20 \%$.
Actual staged IORF in Liaohe (SP1) is $16.3 \%$ OOIP, and the current recovery factor is 66\% OOIP [15]. Water flooding recovery before SP flooding in Liaohe is $49.9 \%$ OOIP. Although some SP flooding field tests (SP1, SP2, and SP7) are very successful if judged by incremental oil recovery, other field tests are not so successful. For instance, ongoing SP3, SP4, and SP5 field tests results are far below expectations. Finished SP6 and SP9 also failed to meet the goal. Inadequate injection schemes and management defects at least partly account for the failure in some SP flooding field tests $[54,103,106,107]$. Lessons from these field tests will be discussed in the next session. More recovery or enhanced oil recovery means more benefits if the oil price exceeds oil production cost. However, if the oil price is lower than the oil production cost, the recovery factor should not be the evaluation criteria. Thus, other parameters like Net Present Value (NPV) [108], output-input ratio (OIR) [3], and utility factor (UF) [109] are also used. Among these parameters, IRF and UF do not depend on oil price, while NPV and OIR highly depends on the oil price. IORF cannot reflect the cost and oil price effect, while UF can partly indicate the cost effect since the polymer price keeps stable during a long period. Due to the limited information available, we can only provide some UF in terms of polymer in Table 1. Figure 6 shows three SP field tests UFs. Current commercial polymer flooding UFs in Daqing [110] shown as " $P$ " in Figure 6 is given for comparison. UF of SP7 is predicted 49 before field test [111], while UF of SP1 is high than 45 [112]. These two field tests are the most successful ones among all the SP flooding field practice. UF of SP6 is 10.1 [86], which indicates the failure. Although RF and UF from SP3, SP4, and SP5 are not made public, some information indicates that these SP flooding performances are not as good as expected. Polymer flooding field test UF from Daqing and Shengli is also given in Figure 6, shown as "P1". From Figure 6, we can see that SP1 and SP7 are economically successful and UF is comparable to that of polymer flooding. SP1 and SP7 and SP6 are currently the most successful SP flooding field tests. However, these large-scale SP flooding field tests UF are much lower than that of early polymer flooding field tests in Daqing and Shengli (P1 in Figure 6). 


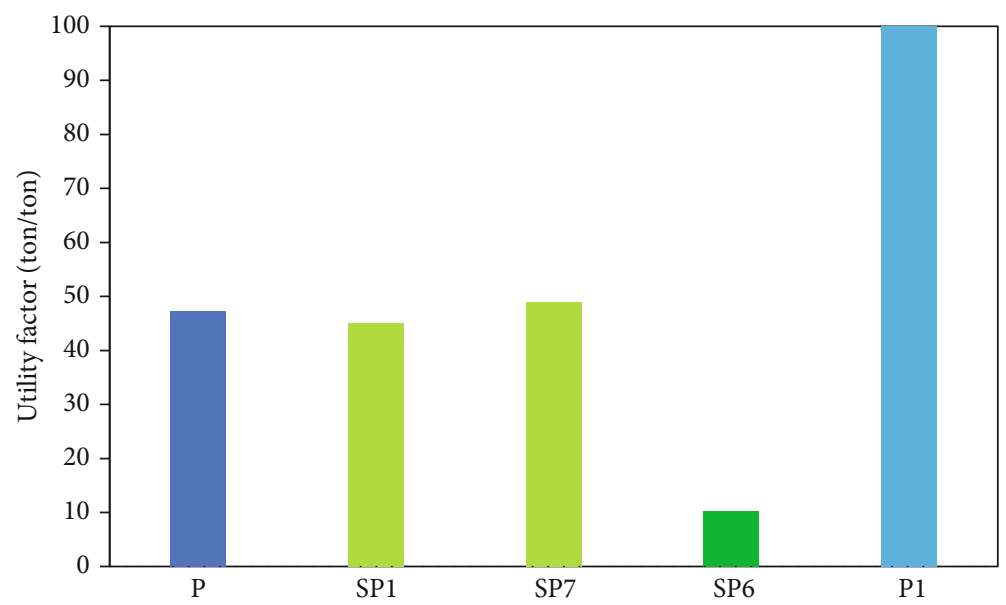

FIGURE 6: Utility factor comparison between polymer flooding and SP flooding.

Since oil production cost is confidential for most oil companies, the actual cost in chemical flooding is not available. Under current oil price circumstances, whether chemical flooding like SP flooding and ASP flooding cost exceeds oil price is of vital importance. ASP flooding field test cost is reported between 30-45 USD/bbl in Daqing [15], while in another study the comprehensive ASP flooding cost without tax is estimated between 28-50 UDS/bbl [113]. SP flooding cost was believed lower than ASP flooding, but higher than polymer flooding. According to a previous study [15], SP flooding cost can be as low as 1000 Yuan/ton (about 21 $\mathrm{USD} / \mathrm{bbl}$ ). This value, however, is too optimistic. It is probably operation cost or chemical cost. It is reported in 2015 that the staged operation cost of SP1 is 1389 Yuan/ton (around 29 $\mathrm{USD} / \mathrm{bbl}$ ) [114]. It is worth to note that SP1 is currently the most successful SP flooding field test which oil production rises from 63 ton/day to 351 ton/day [11]. Table 3 is the cost estimation between polymer flooding, SP flooding, and ASP flooding. The first columns are from the reference [15], while the column with an asterisk $\left({ }^{*}\right)$ is an optimistic estimation based on reference [15]. The last column with a pound sign $\left({ }^{\#}\right)$ in Table 3 is an estimation based on data from reference [114]. It can be seen that even the most successful SP flooding is not cost competitive in current low oil price circumstances, and the cost of SP flooding can be as high as or higher than ASP flooding. Surfactant cost mainly accounts for the high price. Thus, much work has to be done to reduce the SP flooding cost [115].

\section{Lessons Learned}

5.1. SP Flooding Technology Is a Very Promising but Also Risky Technology. From Tables 1 and 3, it is obvious that not all SP flooding makes high or expected IORF. Among the 10 SP field tests in Tables 1 and 2, only SP7, SP1, and SP 2 are reported high IRFs. More information about SP7 is available in reference [70]. Central producer performance of SP7 is shown in Figure 7 [70]. In Figure 7, "0309" means September 2003. The maximum oil production increased by 12 times, the highest among all the SP flooding field tests. In contrast, daily maximum oil production increased by 5
TABLE 3: Cost comparison between polymer, SP, and ASP flooding.

\begin{tabular}{lccccc}
\hline Content & Polymer & ASP & SP & SP $^{*}$ & SP1 $^{\#}$ \\
\hline Construction cost (Yuan/ton) & 350 & 550 & $/$ & 360 & 550 \\
Chemicals cost (Yuan/ton) & 250 & 625 & $/$ & 570 & 481 \\
Operation cost (Yuan/ton) & 325 & 650 & $/$ & 500 & 1389 \\
Total (Yuan/ton) & 925 & 1825 & 1000 & 1430 & 2420 \\
Total (USD/bbl) & 19.4 & 38.5 & 21.1 & 28.9 & 51.8 \\
\hline
\end{tabular}

times in SP1 [11]. The oil production rate of SP1 (Liaohe) and SP2 (Xinjiang) is shown in Figure 8 [116]. However, the daily oil rate in SP1 and SP2 is much more drastic than that of SP7. Causes remain to be studies. The success of SP7 in Shengli Oilfield leads to many enlarged SP flooding field tests and finally industrial promotion of SP in 2008 in Shengli [117]. The success of SP2 in Xinjiang Oilfield also leads to a much more enlarged industrial SP flooding test [116]. Oil production from SP flooding in Shengli in 2016 is more than 2 million tons, and the average IORF is $10.2 \%$ OOIP [117]. Considering the high oil viscosity and high temperature in Shengli, IORF of $10.2 \%$ is quite high. It is not known yet whether the 10.2\% IORF in SP flooding in Shengli is actual field practice performance or merely predicted value. Other field tests or practices of SP flooding in Shengli are not as successful as SP7 and are seldom reported. It is worth to mention that the final recovery factor of SP7 is $54.3 \%$ OOIP, while before SP flooding the water flooding recovery is $36.3 \%$ OOIP [117]. It is generally accepted that the higher recovery factor, the more difficult to enhanced oil recovery, thus it is much easier to enhance oil recovery at higher remaining oil saturation. Perhaps due to the risk or unsatisfactory effects of actual SP flooding performance, another new technology called heterogeneous combination flooding system (HCFS) consisting of polymer, surfactant, and preformed particle gel has been developed with great effort in Shengli [118]. HCFS can be seen as PPG enhanced SP flooding [119]. After some field tests, HCFS has been widely promoted in Shengli Oilfield since 2015 [120]. Since all chemical flooding field tests or applications adopted profile control slug before 


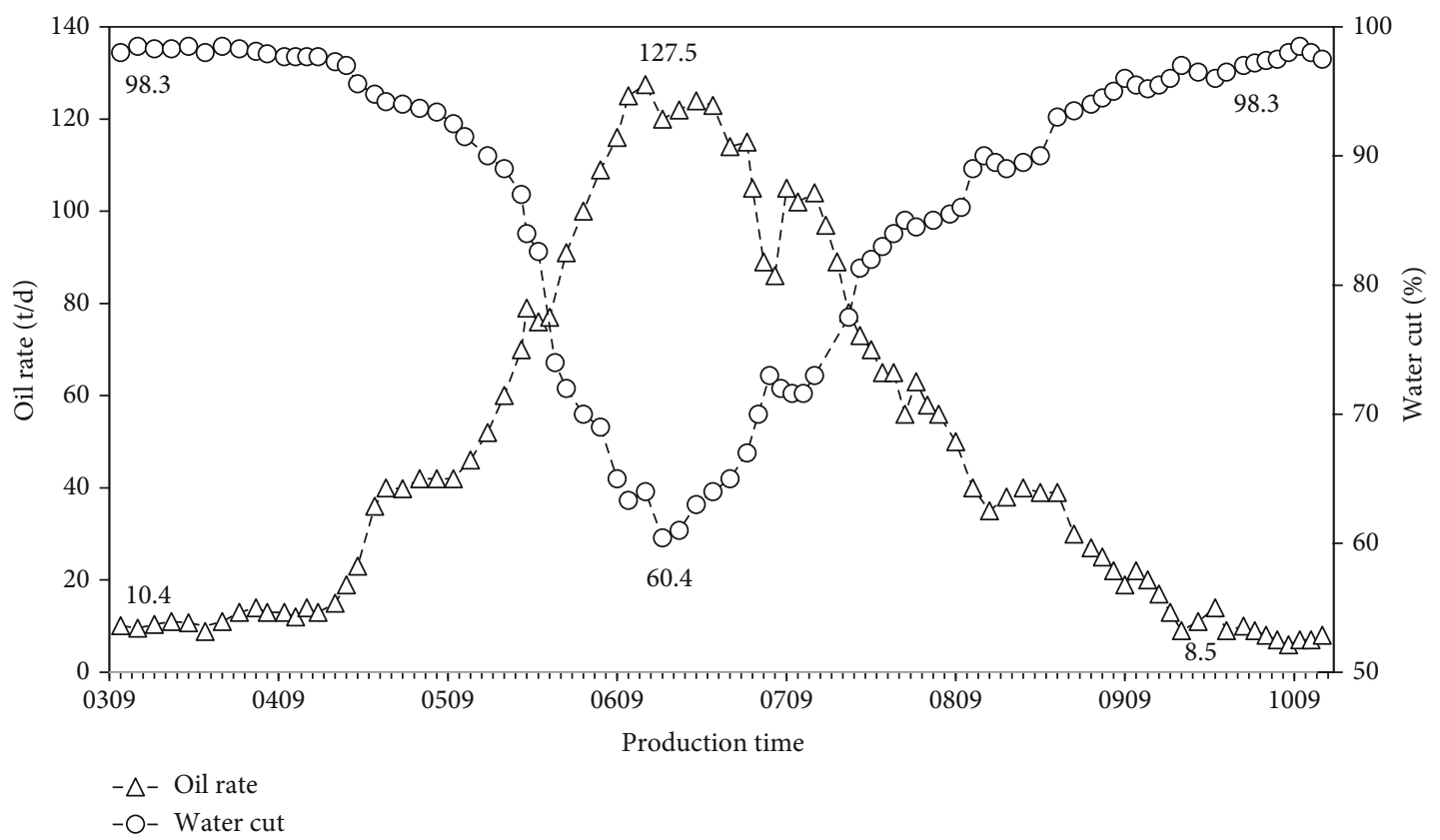

Figure 7: Central block producers performance of SP7 in Shengli [70].

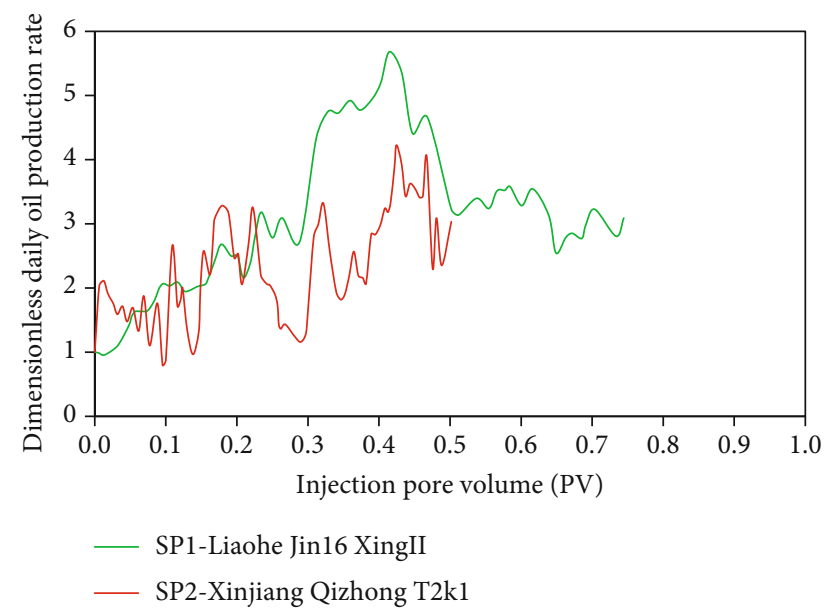

FIGURE 8: Oil production rate performance [116].

chemicals injection, it is not clear that whether it is PPG or SP mainly works in PPG enhanced SP flooding.

\subsection{The Economic Performance of some SP Flooding Was Not} as Attractive as Expected. Table 3 gives the expected SP flooding cost (third column) and actual field tests SP flooding cost (last column, SP\#). In SP\#, only construction cost is estimated the same as that of ASP, considering the same well injection facilities between SP flooding and ASP flooding. There is no alkali facility in SP flooding actually, but the cost increase in ASP flooding can be balanced by more oil produced. Other data in SP\# is collected from reference [114], which is based on the most successful SP1 in recent years. Even a very high IRF is achieved in SP1; its cost is high too. The cost of main chemical flooding techniques is given in Figure 9. Without alkali, the surfactant cost is high due to increased surfactant quality and quantity. Even the most suc-

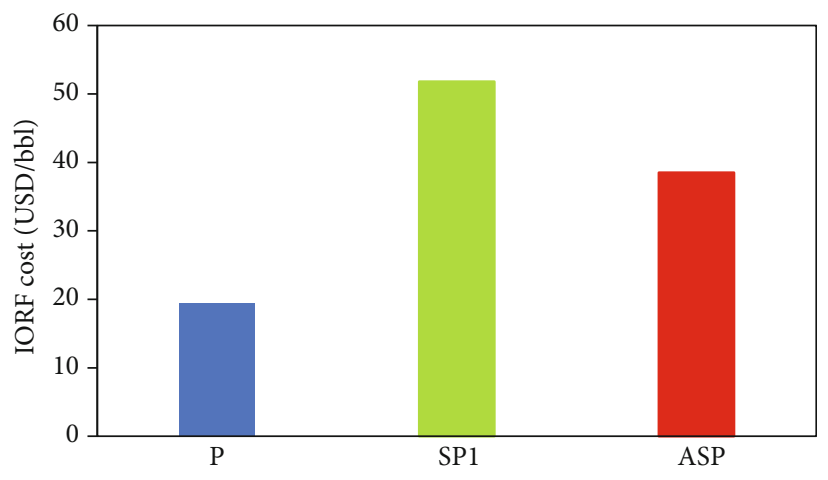

FIgURE 9: Different chemical flooding EOR techniques cost.

cessful SP flooding test (SP1) has a much higher total EOR cost than polymer flooding and ASP flooding. High surfactant cost due to high concentration compared with polymer and high surfactant price mainly accounts for the high cost. In SP6 and SP7, high concentration surfactant is used, which at least partly accounts for the success. Since no special measures are taken to reduce surfactant adsorption like alkali in ASP flooding, the actual surfactant adsorption in strata is high. Surfactant adsorption value with measures taken in SP6 is $4.17 \mathrm{mg} / \mathrm{g}$ sand [111]. Some study [121] indicates that the low IFT state can be only maintained for a very small distance from injectors. The desorption of some surfactant may contribute to reducing IFT; however, whether this contribution results in ultra-low IFT remains to be investigated.

5.3. It Is Very Difficult to Use SP Flooding in Low Permeability Reservoirs. Since surfactant adsorption in low permeability reservoir is much higher than that for higher permeability one, it is theoretically difficult or impossible for surfactant flooding in low permeability reservoirs. This may explain 


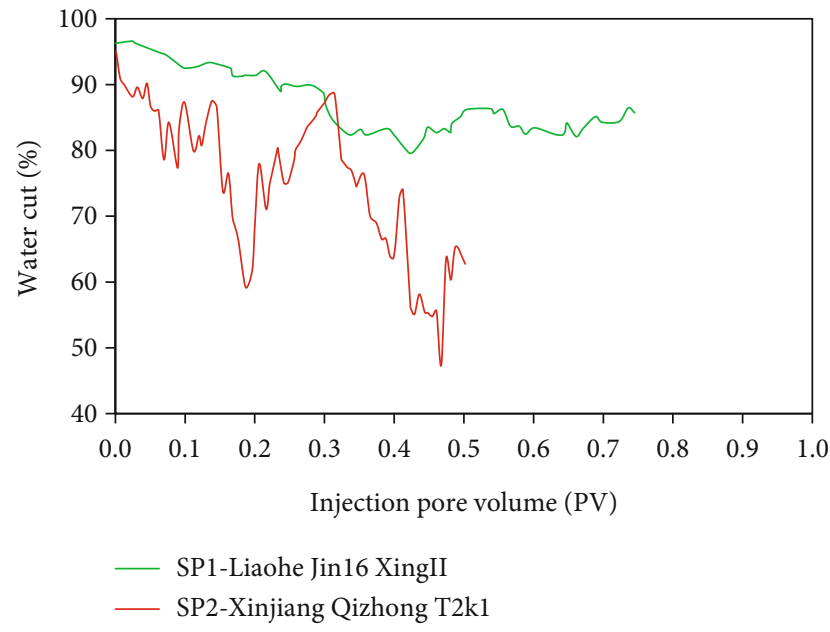

FIGURE 10: Water cut performances [116].

why no SP flooding was reported technical successful in low permeability reservoirs in China. In fact, until 2009, no commercial surfactant flooding projects were reported in the world according to a critical review [95]. It is worthy to mention that SP flooding was reported to use commercially in Shengli Oilfield [96], although few publications were available. To assure the development effect of surfactant flooding, either higher surfactant concentration and/or measures to reduce surfactant adsorption in formation should be used. This will add to the cost. In another successful SP field test in Hungary [17], high concentration surfactant (1.5\%) was used together with a pretreatment potassium chloride $(\mathrm{KCl})$ injection to reduce surfactant adsorption. IFT in the oilwater interface is estimated $10^{-2} \mathrm{mN} / \mathrm{m}$ [17], while the basic requirement of surfactant is to reduce IFT to $10^{-3} \mathrm{mN} / \mathrm{m}$ at a concentration $0.3 \%$ in China. Since most surfactants are adsorbed in near injectors regions, the necessity of reducing IFT by surfactant to $10^{-3} \mathrm{mN} / \mathrm{m}$ as a criterion is worth further investigation.

\subsection{Polymer Viscosity and Concentration Should Be Carefully} Selected in SP Flooding. If polymer concentration and viscosity is too high, strata may be blocked $[122,123]$. If polymer centration and viscosity is too low, the mobility reduction is inadequate. Recently, there are increasing interests in polymer viscoelasticity which is reported to have a great effect on ROS [22, 124-128]. However, the risk of blocking strata should be given priority when high concentration and high molecular weight polymer is injected since the blocking is irreversible in reservoir conditions. Among some not successful field tests, SP2, SP3, and SP4 are all suffered serious blocking in strata, especially SP2. High concentration polymer was believed beneficial to polymer flooding due to its viscoelasticity effect to reduce ROS [129]; however, it does have great risk to block low permeability strata. This is well reflected in SP2, where significant change also called dynamic adjustment has been made [116]. Since the field test block permeability in the north part $(94.8 \mathrm{mD})$ is higher than in the south part $(46 \mathrm{mD})$, with the same injection scheme, production performance in the north part is much better than that in the south part after polymer concentration was gradually reduced [130]. In contrast, at the polymer high concentration injection stage, the production performance was not good. After both polymer concentration and molecular weight $(\mathrm{Mw})$ were reduced significantly, the oil production performance got better [116]. The southern SP flooding was terminated in advance. This cease in advance means at least some kind of failure. More information about SP2 polymer viscosity adjustment is available in reference [116]. For high permeability strata of SP1 in Liaohe, when the polymer concentration was reduced, the field test production performance tended to get worse [112]. After the concentration was increased, the production performance got better. The failure of SP6 has much to do with the water channel, which is not plugged by profile control techniques. The polymer concentration and $\mathrm{Mw}$ was low in view of the temperature and high water cut in SP6. Thus, proper selection polymer is the key to SP flooding. Other important factors concerning polymer viscosity include bacteria and reducibility ions like Sulphur iron and ferrous ion $\left(\mathrm{Fe}^{2+}\right)$ in injection pipelines and produced water. Viscosity can be seriously damaged by pipeline deposits. In SP2, viscosity was increased by $35 \%$ after the $\mathrm{H}_{2} \mathrm{~S}$ and $\mathrm{Fe}^{2+}$ were removed in water used for polymer preparing [130]. At the early stage of SP flooding in Xinjiang (SP2), the viscosity loss from the pump outlet to injectors was as high as $38.07 \%$ [131]. After taking measures, the polymer viscosity loss from makeup to injectors was lower than $10 \%$ [131]. Oxygen and ions has a significant effect on polymer viscosity, and this has been well studied $[127,132,133]$. Thus, one advice for polymer and SP flooding is to carefully check the pipeline to control Sulphur iron and Ferrous ion as well as oxygen content. If the polymer is prepared by produced water, the water quality should be carefully studied to meet requirements.

\section{Discussion}

Although many chemical flooding field tests in China were reported high IORFs, the IORF values are often overestimated. One reason is that many measures like fracturing and acidizing are taken in chemical flooding stage. When calculating water flooding recovery, the contributions of these measures are not deduced. Since the operation levels vary from companies, the comparison between different field tests produces some errors. In addition, SP flooding started at different comprehensive water cut and this provides more difficulty to compare. If one chemical flooding field test started at a higher water cut and gets a higher water cut drop than others, it can be regarded as better than others. However, if it starts at a lower water cut and gets a higher water cut drop, its performance cannot be regarded better. Since there is no identical the same reservoir, a comparison between different projects provides limited reference. Figure 10 is the water cut change between SP1 and SP2. Although SP2 has much more obvious water cut reduction, we cannot say SP2 has better performance than SP1 even other conditions are assumed the same. It is quite strange that the water cut in SP2 goes so drastic. Since detailed production information is not available, we cannot explain it. Production enhancement 


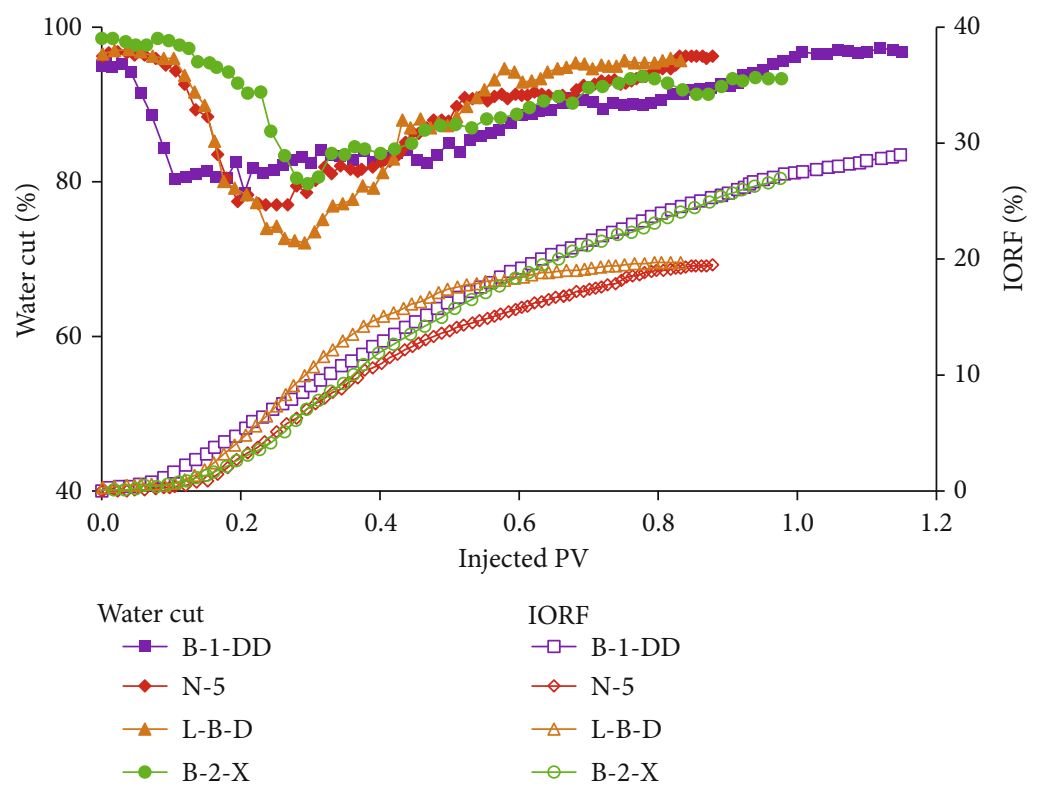

FIGURE 11: Semicommercial ASP flooding tests performance in Daqing [9].

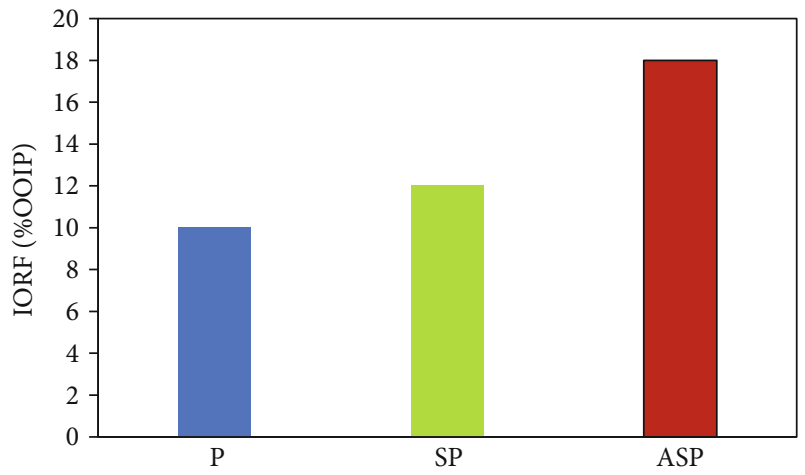

Figure 12: IORF of typical chemical flooding EOR techniques.

measures may account for this. It is also quite strange that the water cut drop of SP1 in Figure 10 is not as good as other polymer flooding and ASP flooding but reported a predicted comparable IORF.

Some ASP flooding field tests water cut change is given in Figure 11 [9]. This ASP flooding reported IORF of $18-28 \%$ OOIP. Besides, the water cut reduction seems more gradual and stable than that of SP flooding in Figure 10. It seems SP7 in Figure 7 has similar water cut shape with ASP flooding. Whether SP flooding is better than ASP flooding is still hard to judge. From these 10 SP flooding field tests, the highest IORF is comparable with that of ASP flooding if taken reservoir difference and management into accounted. However, SP flooding seems to be more challenging than ASP flooding if judged by IORF. Figure 12 shows the IORF of polymer, SP, and ASP for medium temperature reservoir. In this figure, IORF of polymer flooding (10\%OOIP) and ASP flooding (18\% OOIP) is from field test proven values in Daqing. IORF of SP flooding (12\% OOIP) is the average predicted value from these ten field tests in Table 1. ASP flooding is well tested in Daqing, and the first and only commercial applica-

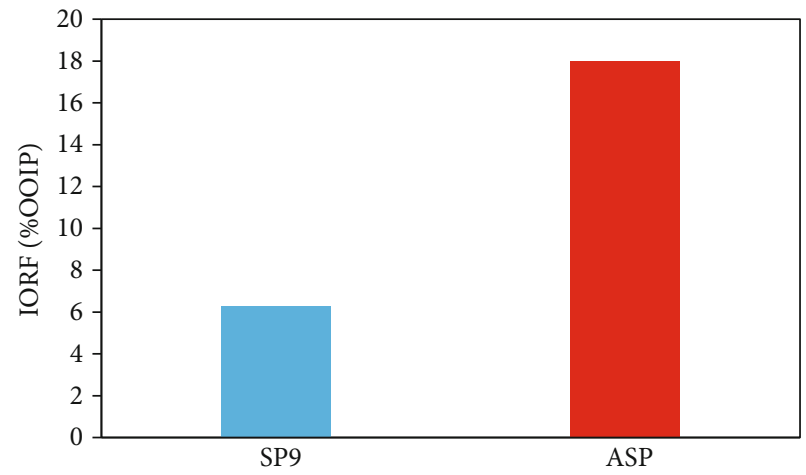

FIGURE 13: IORF between SP flooding and ASP flooding in Daqing.

tion was reported. Most ASP flooding field tests have been conducted in Daqing [4]. However, only one SP flooding in Daqing is reported. Figure 13 shows the SP and ASP IORF comparison under Daqing reservoir condition. Since SP9 in Figure 13 is conducted in a postpolymer flooding reservoir, if assuming an IORF of 10\% OOIP for polymer flooding, SP9 is predicted $16 \%$ OOIP, much lower than average IORF of $18 \%$ OOIP which is verified by many field tests. It is to be noted that SP9 IORF is only predicted. Actual IORF is much lower than this value. If IORF (Figures 12 and 13) and EOR cost (Figure 9) are used as the criteria, SP flooding is not as good as ASP flooding. This is not in agreement with many publications. Please keep in mind that SP flooding was reported to have been used commercially in 2008 .

\section{Conclusions}

SP flooding is a very promising but also challenging chemical EOR technique. Field tests indicate SP flooding can make an IORF of $20 \%$ OOIP in a high permeability reservoir in Liaohe Oilfield. Oil increase in SP7 is as high as 12 times. 
Although some SP flooding field tests are very successful, others fail to meet the design goal of IORF. High surfactant concentration is necessary for the success of SP flooding when surfactant adsorption in strata is taken into consideration.

Adequate polymer viscosity helps to reduce displacing phase mobility but avoid causing blocking to strata. Bacteria and reducibility ions like Sulphur iron and ferrous ion in injection pipelines and produced water seriously affect polymer viscosity. High $\mathrm{Mw}$ and concentration polymer is only possible for high permeability formation.

Since most surfactants are adsorbed in near-injector regions, the necessity of reducing IFT by surfactant to $10^{-3} \mathrm{mN} / \mathrm{m}$ as a criterion is worth investigation.

Although SP flooding is regarded more competitive than ASP flooding by many researches, the actual field test result shows that the comprehensive cost of SP flooding can be as high as ASP flooding. SP flooding is regarded as not as good as ASP flooding at least under Daqing reservoir condition.

Without economic surfactants and good measures to reduce surfactant adsorption to accepted low level, SP flooding is only possible for a high permeability reservoir. It should be very careful to use SP flooding in low permeability reservoir since all field tests seem to go without success.

UF, IORF, and total EOR cost should be used together to evaluate SP flooding field tests for cautious reference.

\section{Nomenclature}

$\begin{array}{ll}\text { EOR: } & \text { Enhanced oil recovery } \\ \text { SP: } & \text { Surfactant-polymer } \\ \text { ASP: } & \text { Alkali-surfactant-polymer } \\ \text { Mw: } & \text { Molecular weight } \\ \text { TDS: } & \text { Total dissolved solids } \\ \text { NA: } & \text { Not available } \\ \text { URF: } & \text { Ultimate recovery factor } \\ \text { IORF: } & \text { Incremental oil recovery factor } \\ \text { NPV: } & \text { Net Present Value } \\ \text { UF: } & \text { Utility factor } \\ \text { OIR: } & \text { Output-input ratio } \\ \text { KPS: } & \text { Karamay petroleum sulfonate } \\ \text { OOIP: } & \text { Original oil in place } \\ \text { HCFS: } & \text { Heterogeneous combination flooding system } \\ \text { PPG: } & \text { Preformed particle gel } \\ \text { ROS: } & \text { Residual oil saturation } \\ \text { IFT: } & \text { Interfacial tension } \\ \text { HPAM: } & \text { Partially hydrolyzed polyacrylamide } \\ \text { CNPC: } & \text { China National Petroleum Company } \\ \text { SINOPEC: } & \text { China Petroleum \& Chemical Corporation } \\ \text { CNOOC: } & \text { China National Offshore Oil Corporation } \\ \text { Inj:: } & \text { Injection } \\ \text { Soi: } & \text { Initial oil saturation } \\ \text { Con: } & \text { Concentration } \\ \text { P: } & \text { Polymer } \\ \text { S: } & \text { Surfactant } \\ \text { PS: } & \text { Petroleum sulfonate } \\ \text { SPS: } & \text { Shengli petroleum sulfonate } \\ \text { KCL: } & \text { Potassium chloride. } \\ & \end{array}$

\section{Data Availability}

The figure and table data used to support the findings of this study are included within the article.

\section{Conflicts of Interest}

The authors declare no conflict of interest.

\section{Authors' Contributions}

Chen Sun and Hu Guo contributed equally to this work.

\section{Acknowledgments}

The authors wish to express their appreciation for the funding provided by National Science and Technology Major Project of China (No. 2016ZX05025-001-005 and No. 2016ZX05025-003-010), the Natural Science Foundation (51834005), the China Scholarship Council (201806440187), and the Deutscher Akademischer Austauschdienst (91737128).

\section{References}

[1] D. W. Green and G. P. Willhite, Enhanced Oil Recovery, Society of Petroleum Engineers, Richardson, 2nd edition, 2018.

[2] H. Guo, Y. Li, F. Wang et al., "ASP flooding: theory and practice progress in China," Journal of Chemistry, vol. 2017, Article ID 8509563, 18 pages, 2017.

[3] H. Guo, Y. Li, Y. Gu, and F. Wang, "Comparison of strong alkali and weak alkali ASP flooding pilot tests in Daqing Oilfield," SPE Production \& Operations, vol. 22, pp. 353-362, 2018.

[4] H. Guo, Y. Li, D. Kong, R. Ma, B. Li, and F. Wang, "Lessons learned from Alkali/Surfactant/Polymer-Flooding field tests in China," SPE Reservoir Evaluation and Engineering, vol. 22, no. 1, pp. 078-099, 2019.

[5] H. Guo, M. Dou, W. Hanqing et al., "Proper use of capillary number in chemical flooding," Journal of Chemistry, vol. 2017, Article ID 4307368, 11 pages, 2017.

[6] Y. Zhu, Q. Hou, G. Jian, D. Ma, and Z. Wang, "Current development and application of chemical combination flooding technique," Petroleum Exploration and Development, vol. 40, no. 1, pp. 96-103, 2013.

[7] H. Cai, Q. Wang, W. Luo et al., "Guerbet alkoxy betaine surfactant for surfactant-polymer flooding in high temperature, high salinity reservoirs," in SPE International Conference on Oilfield Chemistry, Galveston, Texas, USA, April 2019.

[8] L. Sun, X. Wu, W. Zhou, X. Li, and P. Han, "Technologies of enhancing oil recovery by chemical flooding in Daqing Oilfield, NE China," Petroleum Exploration and Development, vol. 45, no. 4, pp. 673-684, 2018.

[9] S. Yuan and Q. Wang, "New progress and prospect of oilfields development technologies in China," Shiyou Kantan Yu Kaifa/Petroleum Exploration and Development, vol. 45, pp. 657668, 2018.

[10] W. Liu, L. Luo, G. Liao, L. Zuo, Y. Wei, and W. Jiang, "Experimental study on the mechanism of enhancing oil recovery by polymer - surfactant binary flooding," Petroleum Exploration and Development, vol. 44, no. 4, pp. 636-643, 2017. 
[11] X. Zhen, Chemical flooding development status and prospect, 7th China Petroleum Society Chemical Enhance Oil Recovery Conference, Dalian, China, 2017.

[12] G. Liao, D. Ma, and Z. Wang, Huge Oilfield Development Tests Practice and Experience, Petroleum Industry Press, Beijing, 1st edition, 2018.

[13] Y. Zhu, "Current developments and remaining challenges of chemical flooding EOR techniques in China," in SPE Asia Pacific Enhanced Oil Recovery Conference, pp. 1-18, Kuala Lumpur, Malaysia, August 2015.

[14] J. J. Sheng, "Mobility control requirement in multiphase displacement processes in porous media," Asia-Pacific Journal of Chemical Engineering, vol. 8, no. 4, pp. 555-566, 2013.

[15] G. Liao, Q. Wang, H. Wang, W. Liu, and Z. Wang, "Chemical flooding development status and prospect," Acta Petrolei Sinica, vol. 38, pp. 196-207, 2017.

[16] Y. Zhu, Q. Hou, R. Weng, G. Jian, Y. Luo, and J. Li, “Recent progress and effects analysis of foam flooding field tests in China," in SPE Enhanced Oil Recovery Conference, pp. 2-4, Kuala Lumpur, Malaysia, April 2013.

[17] S. Puskas, Á. Vágó, M. Törő et al., "First surfactant-polymer EOR injectivity test in the Algyő field, Hungary," in IOR 2017 - 19th European Symposium on Improved Oil Recovery, pp. 1-18, Stavanger, Norway, April 2017.

[18] H. She, D. Kong, Y. Li, Z. Hu, and H. Guo, "Recent advance of microbial enhanced oil recovery (MEOR) in China," Geofluids, vol. 2019, Article ID 1871392, 16 pages, 2019.

[19] R. S. Seright, "How much polymer should be injected during a polymer flood ? Review of previous and current practices," SPE Journal, vol. 22, no. 1, pp. 001-018, 2017.

[20] A. Clarke, A. M. Howe, J. Mitchell, J. Staniland, and L. A. Hawkes, "How viscoelastic polymer flooding enhances displacement efficiency," SPE Journal, vol. 21, no. 3, pp. 06750687, 2016.

[21] J. J. Sheng, B. Leonhardt, and N. Azri, "Status of polymerflooding technology," Journal of Canadian Petroleum Technology, vol. 54, no. 2, pp. 116-126, 2015.

[22] P. Qi, D. H. Ehrenfried, H. Koh, and M. T. Balhoff, "Reduction of residual oil saturation in sandstone cores by use of viscoelastic polymers," SPE Journal, vol. 22, no. 2, pp. 447-458, 2017.

[23] E. C. M. Vermolen, M. J. T. van Haasterecht, and S. K. Masalmeh, "A systematic study of the polymer visco-elastic effect on residual oil saturation by core flooding," in SPE EOR Conference at Oil and Gas West Asia, pp. 1-14, Muscat, Oman, 2014.

[24] R. S. Seright, G. Zhang, O. O. Akanni, and D. Wang, "A comparison of polymer flooding with in-depth profile modification," Journal of Canadian Petroleum Technology, vol. 51, pp. 393-402, 2013.

[25] D. Wang, H. Xia, S. Yang, and G. Wang, "The influence of visco-elasticity on micro forces and displacement efficiency in pores,cores and in the field," in SPE EOR Conference at Oil \& Gas West Asia, pp. 1-18, Muscat, Oman, April 2010.

[26] H. Zhong, Q. Zang, H. Yin, and H. Xia, "Experimental study on medium viscosity oil displacement using viscoelastic polymer," Geofluids, vol. 2018, Article ID 4321380, 11 pages, 2018.

[27] Y. Liu, J. Fan, L. Liu, and S. Yang, "Numerical simulation of residual oil flooded by polymer solution in microchannels," Geofluids, vol. 2018, Article ID 8947839, 10 pages, 2018.
[28] H. Zhong, W. Zhang, H. Yin, and H. Liu, "Study on mechanism of viscoelastic polymer transient flow in porous media," Geofluids, vol. 2017, Article ID 8763951, 8 pages, 2017.

[29] Y. Fang, E. Yang, D. Yin, and Y. Gan, "Study on distribution characteristics of microscopic residual oil in low permeability reservoirs," Journal of Dispersion Science and Technology, vol. 41, no. 4, pp. 575-584, 2020.

[30] Y. Fang, E. Yang, D. Yin, and Y. Gan, "Study on distribution characteristics of microscopic residual oil in low permeability reservoirs," Geofluids, vol. 2019, Article ID 9752623, pp. 112, 2019.

[31] D. Wang, G. Wang, W. Wu, H. Xia, and H. Yin, "The influence of viscoelasticity on displacement efficiency from micro- to macroscale," in SPE Annual Technical Conference and Exhibition, pp. 1-10, Anaheim, California, USA, 2007.

[32] A. A. Olajire, "Review of ASP EOR (alkaline surfactant polymer enhanced oil recovery) technology in the petroleum industry: prospects and challenges," Energy, vol. 77, pp. 963-982, 2014.

[33] Y. Li, W. Zhang, B. Kong et al., "Mixtures of anionic-cationic surfactants: a new approach for enhanced oil recovery in lowsalinity, high-temperature sandstone reservoir," SPE Journal, vol. 21, no. 4, pp. 1164-1177, 2016.

[34] J. G. Southwick, E. van den Pol, C. H. T. van Rijn et al., "Ammonia as alkali for alkaline/surfactant/polymer floods," SPE Journal, vol. 21, no. 1, pp. 010-021, 2016.

[35] A. Kazemi Nia Korrani, K. Sepehrnoori, and M. Delshad, “A mechanistic integrated geochemical and chemical flooding tool for alkaline/surfactant/polymer floods," SPE Journal, vol. 21, no. 1, pp. 032-054, 2016.

[36] S. M. Hosseini-Nasab, C. Padalkar, E. Battistutta, and P. L. J. Zitha, "Mechanistic modeling of the alkaline/surfactant/polymer flooding process under sub-optimum salinity conditions for enhanced oil recovery," Industrial and Engineering Chemistry Research, vol. 55, no. 24, pp. 6875-6888, 2016.

[37] H. Sharma, S. Dufour, G. W. P. P. Arachchilage, U. Weerasooriya, G. A. Pope, and K. Mohanty, "Alternative alkalis for ASP flooding in anhydrite containing oil reservoirs," Fuel, vol. 140, pp. 407-420, 2015.

[38] L. He, F. Lin, X. Li, H. Sui, and Z. Xu, "Interfacial sciences in unconventional petroleum production: from fundamentals to applications," Chemical Society Reviews, vol. 44, no. 15, pp. 5446-5494, 2015.

[39] X. Zhou, M. Dong, and B. Maini, “The dominant mechanism of enhanced heavy oil recovery by chemical flooding in a twodimensional physical model," Fuel, vol. 108, pp. 261-268, 2013.

[40] H. Pei, G. Zhang, J. Ge, L. Jin, and C. Ma, "Potential of alkaline flooding to enhance heavy oil recovery through water-inoil emulsification," Fuel, vol. 104, pp. 284-293, 2013.

[41] H. Pei, G. Zhang, J. Ge, L. Jin, and X. Liu, “Analysis of microscopic displacement mechanisms of alkaline flooding for enhanced heavy-oil recovery," Energy and Fuels, vol. 25, no. 10, pp. 4423-4429, 2011.

[42] H. Zhang, M. Dong, and S. Zhao, "Which one is more important in chemical flooding for enhanced court heavy oil recovery, lowering interfacial tension or reducing water mobility?," Energy and Fuels, vol. 24, no. 3, pp. 1829-1836, 2010.

[43] Q. Liu, M. Dong, X. Yue, and J. Hou, "Synergy of alkali and surfactant in emulsification of heavy oil in brine," Colloids 
and Surfaces A: Physicochemical and Engineering Aspects, vol. 273, no. 1-3, pp. 219-228, 2006.

[44] N. Pal, N. Saxena, and A. Mandal, "Phase behavior, solubilization, and phase transition of a microemulsion system stabilized by a novel surfactant synthesized from castor oil," Journal of Chemical \& Engineering Data, vol. 62, no. 4, pp. 1278-1291, 2017.

[45] H. Pei, G. Zhang, J. Ge, J. Zhang, and Q. Zhang, "Investigation of synergy between nanoparticle and surfactant in stabilizing oil-in-water emulsions for improved heavy oil recovery," Colloids and Surfaces A: Physicochemical and Engineering Aspects, vol. 484, pp. 478-484, 2015.

[46] M. S. Karambeigi, R. Abbassi, E. Roayaei, and M. A. Emadi, "Emulsion flooding for enhanced oil recovery: interactive optimization of phase behavior, microvisual and core-flood experiments," Journal of Industrial and Engineering Chemistry, vol. 29, pp. 382-391, 2015.

[47] Z. Chen, X. Zhao, Z. Wang, and M. Fu, "A comparative study of inorganic alkaline/polymer flooding and organic alkaline/polymer flooding for enhanced heavy oil recovery," Colloids and Surfaces A: Physicochemical and Engineering Aspects, vol. 469, pp. 150-157, 2015.

[48] A. Bera, T. Kumar, K. Ojha, and A. Mandal, "Screening of microemulsion properties for application in enhanced oil recovery," Fuel, vol. 121, pp. 198-207, 2014.

[49] J. Wang, M. Han, A. B. Fuseni, and D. Cao, "Surfactant adsorption in surfactant-polymer flooding for carbonate reservoirs," in SPE Middle East Oil \& Gas Show and Conference, p. 872, Manama, Bahrain, 2015.

[50] N. U. Karasinghe, P. J. Liyanage, J. Cai et al., "New surfactants and co-solvents increase oil recovery and reduce cost," in SPE Improved Oil Recovery Conference, pp. 1-34, Tulsa, Oklahoma, USA, April 2016.

[51] H. Sharma, J. Lu, U. P. Weerasooriya, G. A. Pope, and K. K. Mohanty, "Adsorption in chemical floods with ammonia as the alkali," in SPE Improved Oil Recovery Conference, pp. 115, Tulsa, Oklahoma, USA, April 2016.

[52] H. Zhang, L. Biao, and J. Wang, "Performance analysis SP flooding in JZ9-3 Bohai," China Cleaning Industry, vol. 5, pp. 43-45, 2014.

[53] L. Qi, Y. Yi, H. Wang, B. Huang, and S. Yang, "JZ9-3 Oilfield SP Flooding Laboratory Study," in 2007 The 4th International Academic Conference of the State Key Laboratory of Oil and Gas Reservoir Geology and Development Engineering, pp. 1328-1334, 2007.

[54] J. Lv, L. Qing, D. Zhang, and J. Zhang, "Surfactant-polymer flooding research and application in conglerate reservoir," in China Oil Gas Development Technology Conference, pp. 339-346, 2018.

[55] C. Jinrong, "Chemical enhanced oil recovery technology outlook for Honggang oilfield," Petroleum knowledge, vol. 3, pp. 1-3, 2018.

[56] Y. Li, B. Kong, W. Zhang et al., "ASP flood with novel mixtures of anionic-cationic surfactants for high water cut mature sandstone reservoir: From laboratory to field application," in SPE Middle East Oil and Gas Show and Conference, pp. 1-17, Manama Bahrain, 2019.

[57] X. Liu, Adaptability of SP flooding in JZ9-3 reservoir, China University of Petroleum-Beijing, Master Thesis, 2010.

[58] H. Bo, "EOR study and analysis of Tandong block in Gangdong oilfield," China Petrochemical, 2017.
[59] C. Du, W. Li, L. Wang, and L. Liu, "Indoor experiment study of polymer-surfactant dual-compound flooding in extra low permeability with high salinity of Changqing oilfield," Low Permeability Oil-Gas Field, vol. 3, pp. 135-137, 2013.

[60] M. Kazempour, E. J. Manrique, V. Alvarado, J. Zhang, and M. Lantz, "Role of active clays on alkaline-surfactantpolymer formulation performance in sandstone formations," Fuel, vol. 104, pp. 593-606, 2013.

[61] W. M. Stoll, H. al Shureqi, J. Finol et al., "Alkaline/surfactant/polymer flood: from the laboratory to the field," SPE Reservoir Engineering, vol. 14, no. 6, pp. 702-712, 2013.

[62] J. He, G. Liao, and Z. Wang, "Oilfield development strategy and replacement techniques," Acta Petrolei Sinica, vol. 33, pp. 519-525, 2012.

[63] Y. Zhu, Y. Zhang, J. Niu, W. Liu, and Q. Hou, “The progress in the alkali-free surfactant-polymer combination flooding technique," Petroleum Exploration and Development (Shiyou Kantan Yu Kaifa), vol. 39, pp. 346-351, 2012.

[64] J. Yang, B. Jin, L. Jiang, and F. Liu, “An improved numerical simulator for surfactant/polymer flooding," in SPE/IATMI Asia Pacific Oil \& Gas Conference and Exhibition, pp. 1-13, Nusa Dua, Bali, Indonesia, 2015.

[65] Q. Lu, Y. Ning, C. T. Branch, J. Wang, and X. Yang, "Full field offshore surfactant-polymer flooding in Bohai Bay China," in SPE Asia Pacific Enhanced Oil Recovery Conference, pp. 1113, Kuala Lumpur, Malaysia, 2015.

[66] X. Kang and J. Zhang, "Surfactant Polymer (SP) Flooding Pilot Test on Offshore Heavy Oil Field in Bohai Bay, China," in SPE Enhanced Oil Recovery Conference, pp. 1-7, Kuala Lumpur, Malaysia, 2013.

[67] W. Xiang and W. Zhou, "Field experience of produced polymer control in offshore oilfield," in SPE Enhanced Oil Recovery Conference, pp. 2007-2010, Kuala Lumpur, Malaysia, 2011.

[68] K. Xiaodong and Z. Jian, "Offshore heavy oil polymer flooding test in JZW area," in SPE Heavy Oil Conference-Canada, pp. 1-13, Calgary, Alberta, Canada, 2013.

[69] M. Kuiqian, L. Yanlai, W. Lilei, and Z. Xiaolin, "Practice of the early stage polymer flooding on LD offshore oilfield in Bohai Bay of China," in SPE Asia Pacific Enhanced Oil Recovery Conference, pp. 1-8, Kuala Lumpur, Malaysia, 2015.

[70] L. Zhenquan, Z. Aimei, X. Cui, Z. Li, G. Lanlei, and S. Liantao, "A successful pilot of dilute surfactant-polymer flooding in Shengli Oilfield," in SPE Improved Oil Recovery Symposium, pp. 1-6, Tulsa, Oklahoma, USA, 2012.

[71] Y. Zhu, Q. Hou, R. Weng, G. Jian, Y. Luo, and J. Li, "Recent progress and effects analysis of foam flooding field tests in China," in SPE Enhanced Oil Recovery Conference, pp. 1-8, Kuala Lumpur, Malaysia, 2013.

[72] Y. Zhu and M. Lei, "Studies on surfactant-polymer combination flooding formulations for a high salinity reservoir," in SPE EOR Conference at Oil and Gas West Asia, pp. 1-9, Muscat, Oman, 2016.

[73] Y. Wang, F. Zhao, B. Bai, J. Zhang, W. Xiang, X. Li et al., "Optimized surfactant IFT and polymer viscosity for surfactant- polymer flooding in heterogeneous formations," in SPE Improved Oil Recovery Symposium, pp. 1-11, Tulsa, Oklahoma, USA, April 2010.

[74] R. Xu, "Investigation on the demulsification mechanism mechanism of combination flooding produced water from 
Gudong reservoir," China University of Petroleum-Beijing, Master thesis, 2011.

[75] D. Feng, Q. Fu, L. Li, S. Huang, Z. Chu, and S. Liu, "Division and application of flow units in $\mathrm{Ng} 52+3$ sand group of Gudong oilfield," Fault-block Oil \& Gas Field, vol. 23, pp. 3-6, 2016.

[76] S. Zhang, "Formula design and application of surfactantpolymer flooding on high temperature and high calcium and heavy oil reservoir," Petrochemical Industry Application, vol. 33, pp. 7-10, 2014.

[77] B. Sun, "SP flooding EOR in Gudong oilfield," Nei Jiang Science Technology, vol. 35, pp. 79-79, 2014.

[78] H. Song, "Research of surfactant-polymer flooding response characteristics and influencing factors-case of Gudong oilfield," Natural Gas Geoscience, vol. 25, pp. 98-105, 2015.

[79] X. Tang, "Field studies to improve SP flooding effect in the Gudong oilfield," China University of Petroluem (East China), Master thesis, 2012.

[80] L. Yang, "The application studies on polymer/SAA binary combination flooding," China University of Petrolem (East China), Master thesis, 2009.

[81] Y. Lu and Y. Ma, "Post-evaluation study of tertiary oil recovery chemical flooding project in Shengli oilfield," Science Technology and Industry, vol. 17, pp. 84-88, 2017.

[82] Z. Wu, X. Yue, F. Zhao, Q. Liu, X. Li, and L. Zhang, "Rheology and interfacial activity distribution of surfactantpolymer system in the seventh block of Gudong oilfield," Oil Drilling and Production Technology, vol. 34, pp. 85-89, 2012.

[83] X. Wang, J. Wang, and L. Zeng, "Surfactant-polymer flooding pilot test in Gudong oilfield," Petroleum Geology and Oilfield Development in Daqing, vol. 29, pp. 151-153, 2010.

[84] W. Wang, "The development effectness factor influence study of two phase component flooding in Shuanghe oilfield," Northeast Petroleum University, Master thesis, 2016.

[85] L. Wu, Y. Sun, X. Zhang, L. Jia, H. Du, and L. He, "Chemical migration mechanism in SP flooding field test in Shuanghe oilfield," Petroleum Geology and Engineering, vol. 28, pp. 103-106, 2014.

[86] S. Zhang, "The study on block 438 in He'nan oilfield numerical simulation of polymer-surfactant flooding," Northeast Petroluem University, Master thesis, 2014.

[87] Y. Liu, B. Kong, L. Xiao, X. Lv, H. Shu, and Y. Lin, "Study on combination flooding enhanced oil recovery technique in ultra-high water cut reservoir," Oilfield Chemistry, vol. 30, 2013.

[88] W. Wenxiang, Z. Dong, K. Liang, and L. Liyuan, "Optimization of alkali agent on performance of ASP system," FaultBlock Oil \& Gas Field, vol. 20, pp. 772-774, 2013.

[89] Y. Guo, S. Li, Z. Han, Q. Wang, M. Hao, J. Wang et al., "Performance evaluation of polymer-surfactant combination flooding system in $80{ }^{\circ} \mathrm{C}$ high temperature reservoir after polymer flooding," Oilfield Chemistry, vol. 30, pp. 74-79, 2013.

[90] H. Huang, T. Wu, B. Kong, Y. Wang, Y. Song, and X. Wang, "Chemical EOR Study and applicaiton in He'nan oilfield," Petroleum Geology and Engineering, vol. 26, pp. 95-101, 2012.

[91] S. Jia, J. Zhang, Q. Wang, W. Cao, G. Wang, and X. Hou, "EOR of surfactant/polymer flooding on P1 group of Daqing oilfield," Science and Technology Engineering, vol. 11, article 7517-7504, 2011.

[92] Z. Dong and W. U. Wen-xiang, "Study on the static adsorption law of SP system," Contemporary Chemical Industry, vol. 44, pp. 2078-2080, 2015.

[93] Y. Shui, "The feasibility study of binary flooding (PHAM/surfactant) and polymeric surfactants flooding on Gaotaizi oil layer in the Saertu oilfield," Jilin University, Master thesis, 2012.

[94] Y. Fan, "The study on residual oil and effective character of surfactant/polymer combined flooding in Sazhong oilfield of Daqing," Northeast Petroleum University, Master thesis, 2013.

[95] G. Hirasaki, C. Miller, and M. Puerto, "Recent advances in surfactant EOR," SPE Journal, vol. 14, no. 4, pp. 889-907, 2013.

[96] C. Gao, J. Shi, and F. Zhao, "Successful polymer flooding and surfactant-polymer flooding projects at Shengli oilfield from 1992 to 2012," Journal of Petroleum Exploration and Production Technologies, vol. 4, no. 1, pp. 1-8, 2014.

[97] J. He, G. Liao, and Y. Wang, Emerging Strategic Technology of the Oilfield Developmen, Petroleum industry press, Beijing, 2nd edition, 2018.

[98] H. Guo, J. Dong, Z. Wang et al., "EOR Survey in China-Part 1 Oil and Gas in China," SPE Improved Oil Recovery Conference, 2018, pp. 1-24, Tulsa, OK, USA, April 2018.

[99] S. Yin, H. Pu, and S. Zhou, "An update on full field implementation of chemical flooding in Daqing oilfield, China, and its future. Society of Petroleum Engineers," in SPE Improved Oil Recovery Conference, Tulsa, Oklahoma, USA, April 2018.

[100] R. S. Seright, A. Campbell, P. Mozley, and P. Han, "Stability of partially hydrolyzed polyacrylamides at elevated temperatures in the absence of divalent cations," SPE Journal, vol. 15, no. 2, pp. 341-348, 2013.

[101] J. J. Taber, F. D. Martin, and R. S. Seright, "EOR screening criteria revisited - part 1: introduction to screening criteria and enhanced recovery field projects," SPE Reservoir Engineering, vol. 12, no. 3, pp. 189-198, 2013.

[102] J. J. Taber, F. D. Martin, and R. S. Seright, "EOR screening criteria revisited-part 2: applications and impact of oil prices," SPE Reservoir Engineering, vol. 12, no. 3, pp. 199-206, 2013.

[103] K. Wang, "Core analysis of Jin 16 chemical flooding. China Pet," in China Petroleum Society 8th Chemcial Enhanced Oil Recovery Conference, 2019.

[104] C. Jiecheng, W. Junzheng, and H. Junqing, "Key theories and technologies for enhanced oil recovery of alkali/surfactant/polymer flooding," Acta Petrolei Sinica, vol. 35, pp. 310318, 2014.

[105] H. Guo, Y. Q. Li, Y. Zhu, F. Y. Wang, D. B. Kong, and R. C. $\mathrm{Ma}$, "Comparison of scaling in strong alkali and weak alkali ASP flooding pilot tests," in IOR 2017 - 19th European Symposium on Improved Oil Recovery, pp. 1-13, Stavanger, Norway, April 2017.

[106] C. Xiao, Y. Wu, T. Yu, Y. Zhang, Y. Zhang, L. Hou et al., "Surfactant-polymer flooding technology research and practice in high watercut and high recovery water flood sandstone," in China Oil Gas Development Technology Conference, pp. 158-162, Beijing, 2018.

[107] X. Nie, "Chemical formula research progress for mediumhigh permeability reservoirs," in China Petroleum Society 
8th Chemcial Enhanced Oil Recovery Conference, Qingdao, China, 2019.

[108] A. Kamari, F. Gharagheizi, A. Shokrollahi, M. Arabloo, and A. H. Mohammadi, "Integrating a robust model for predicting surfactant-polymer flooding performance," Journal of Petroleum Science and Engineering, vol. 137, pp. 87-96, 2016.

[109] M. Sieberer, K. Jamek, and T. Clemens, "Polymer-flooding economics, from pilot to field implementation," SPE Economics \& Management, vol. 9, no. 3, pp. 51-60, 2017.

[110] M. Sieberer, T. Clemens, J. Peisker, and S. Ofori, "Polymer-flood field implementation: pattern configuration and horizontal vs. vertical wells," SPE Reservoir Evaluation \& Engineering, vol. 22, no. 2, pp. 577-596, 2019.

[111] H. Sun, Z. Li, X. Cao, and Y. Jiang, Surfactant-Polymer Flooding Technology, China Science and Technology Press, Beijing, 1st edition, 2007.

[112] H. Tang, "SP flooding development performance and dynamic change technology," in China Petroleum Society 7th Chemical Enhanced Oil Recovery Conference, Dalian, China, July 2017.

[113] H. Guo, Y. Q. Li, R. C. Ma, F. Y. Wang, and Z. Shihu, "Evaluation of three large scale ASP flooding field test," in IOR 2017 - 19th European Symposium on Improved Oil Recovery, pp. 1-11, Stavanger, Norway, April 2017.

[114] X. Wei, H. Lu, and G. Wang, "Different development pattern economical benefits difference evaluation in Jin 16, Liaohe oilfield," Petrochemical Management, vol. 2, pp. 212-213, 2015.

[115] W. Yi, "Consideration and suggestion on development technology for Liaohe oilfield," Special Oil Gas Reserve, vol. 25, pp. 96-100, 2018.

[116] M. Gao, J. Lv, J. Gao et al., "The characteristics and adjustment technology of surfactant/polymer binary flooding in conglomerate reservoir," in SPE Kingdom of Saudi Arabia Annual Technical Symposium and Exhibition, p. 10, Dammam, Saudi Arabia, April 2018.

[117] H. Wang, S. Guo, B. Pan, Z. Li, and F. Li, "SP flooding technology in Shengli," in China Petroleum Society 7th Chemical Enhanced Oil Recovery Conference, pp. 866-874, Daqing, China, July 2017.

[118] X. Cao, "Design and performance evaluation on the heterogeneous combination flooding system," Acta Petrolei Sinica (Petroleum Processing Section), vol. 29, pp. 115-121, 2013.

[119] X. H. Cui, Z. Q. Li, X. L. Cao, X. W. Song, and X. Zhang, "Inst SORES. A novel Ppg enhanced surfactant-polymer system for EOR," in SPE Enhanc. Oil Recover. Conf, pp. 1-8, Kuala Lumpur, Malaysia, July 2011.

[120] L. Guo, "PPG enhanced SP flooding technolgy in Shengli," in China Petroleum Society 7th Chemical Enhanced Oil Recovery Conference, pp. 1-10, Dalian, China, July 2017.

[121] L. Gang, H. Jirui, L. Qiuyuan, W. Shaopeng, L. Mingyuan, and L. Shuai, "Chemicals loss and effective distance of ASP flooding in second-class oil layers," Journal of China University of Petroleum (Edition of Natural Science), vol. 39, pp. 171-177, 2015.

[122] H. Guo, "How to select polymer molecular weight and concentration to avoid blocking? Field Practices Experience," in IOR 2019 - 20th European Symposium on Improved Oil Recovery, pp. 1-15, Pau, France, April 2019.

[123] H. Guo, "How to select polymer molecular weight and concentration to avoid blocking in polymer flooding?," in SPE
Symposium: Production Enhancement and Cost Optimisation, p. 1996, Kuala Lumpur, Malaysia, November 2017.

[124] H. Koh, V. B. Lee, and G. A. Pope, "Experimental investigation of the effect of polymers on residual oil saturation," SPE Journal, vol. 23, no. 1, pp. 001-017, 2018.

[125] M. Z. Erincik, P. Qi, M. T. Balhoff, and G. A. Pope, "New method to reduce residual oil saturation by polymer flooding," SPE Journal, vol. 23, no. 5, pp. 1994-1956, 2018.

[126] S. Jouenne, H. Chakibi, and D. Levitt, "Polymer stability after successive mechanical-degradation events," SPE Journal, vol. 23, no. 1, pp. 018-033, 2018.

[127] M. S. Azad and J. J. Trivedi, "Quantification of the viscoelastic effects during polymer flooding: a critical review," SPE Journal, vol. 24, no. 6, pp. 2731-2757, 2019.

[128] Y. Guo, Y. Liang, M. Cao et al., "Flow behavior and ViscousOil-Microdisplacement characteristics of hydrophobically modified partially hydrolyzed polyacrylamide in a repeatable quantitative visualization micromodel," SPE Journal, vol. 22, no. 5, pp. 1448-1466, 2017.

[129] S. Gao, Z. Jiang, K. Zhang et al., "High concentration polymer flooding field test with well infilling to change fluid flowing direction after polymer flooding," in SPE EOR Conference at Oil and Gas West Asia, pp. 1-12, Muscat, Oman, March 2016.

[130] Z. Nie, "Practice and lessons learned from SP flooding field test in Xinjiang conglomerate reservoir," in 7th China Petroleum Society Chemcical Flooding Enhanced Oil Recovery Conference, pp. 1-5, Dalian, China, July 2017.

[131] M. Zhao, M. Ding, Y. Wu, and D. Wang, "Surface facility management and innovation in 7ZQ surfactant-polymer flooding field test," in Proceedings of Polymer-surfactant Flooding Technology, pp. 587-591, Petroleum Industry Press, Beijing, 2014.

[132] H. Wan and R. S. Seright, "Is polymer retention different under anaerobic vs. aerobic conditions?," SPE Journal, vol. 22, no. 2, pp. 431-437, 2017.

[133] R. Seright and I. Skjevrak, "Effect of dissolved iron and oxygen on stability of Hydrolyzed Polyacrylamide polymers," SPE Journal, vol. 20, no. 3, pp. 433-441, 2015. 